\title{
Legislation on the preparation of medicinal products in European pharmacies and the Council of Europe Resolution
}

\author{
H PA Scheepers, ${ }^{1}$ J Langedijk, ${ }^{2}$ V Neerup Handlos, ${ }^{3}$ S Walser, ${ }^{4}$ M H Schutjens, ${ }^{5}$ \\ C Neef ${ }^{6,7}$
}

For numbered affiliations see end of article.

Correspondence to H P A Scheepers, Ministry of Health, Welfare and Sport, Health Care Inspectorate, Stadsplateau 1, Utrecht 3521 AZ, The Netherlands; hp.scheepers@igz.nl

HPAS is Coordinating Specialist Senior Inspector at the Dutch Health Care Inspectorate. The views expressed in this article are the personal views of the authors and may not be understood or quoted as being made on behalf of or reflecting the position of the Dutch Health Care Inspectorate. After the completion of the study JL obtained a position at Brabers that provides strategic, legal and public affairs advice to (associations of) companies that operate in regulated markets including pharma. MHS is a consultant for several parties involved in the manufacturing, preparing and distributing of medicinal products, including pharmaceutical companies and preparing and distributing pharmacies.

Received 10 June 2016 Revised 18 July 2016 Accepted 12 August 2016 Published Online First 5 September 2016

EAHP Statement 3 : Production and Compounding

\section{SLinked}

- http://dx.doi.org/10.1136/ ejhpharm-2016-001017

\section{CrossMark}

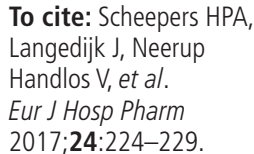

\begin{abstract}
Introduction The rights of patients should be sufficiently protected even when an appropriate authorised medicine does not exist or is unavailable on the market. The Resolution, which was adopted by the Committee of Ministers of the Council of Europe in 2011, aims at harmonising quality and safety standards for pharmacy preparation of medicinal products in Europe.
\end{abstract}

Two pillars of EU regulation and the exceptions to them The system of regulation of medicinal products is built upon two pillars: the marketing authorisation of the medicinal product and the licence for manufacturing and wholesale. This article provides insight into the recent interpretation of the European Court of Justice concerning the scope of European Union (EU) regulation of medicinal products and the circumstances in which the EU regulation does not apply: pharmacy preparations, specialties and the compassionate use of medicines, including manufacturing licence.

EU regulation and the Resolution concerning pharmacy preparation Pharmacy preparations are allowed under certain strict conditions according to EU regulations. However, pharmacies specialised in preparation and distributing medicinal products to local pharmacies do not fulfil these strict conditions in EU regulation. Apart from the legal context, relevant standards for safety and quality assurance are needed in Europe in order to protect patients' rights and to avoid risks from pharmacy preparations.

Discussion and conclusions The Council of Europe Resolution provides a means of establishing standards for safety and quality assurance for pharmacy preparations through Good Manufacturing Practice Guidelines. The Resolution is available to authorities and pharmacists in order to prevent incidents with medicines prepared in pharmacies which may threaten patients' safety. The authors conclude that pharmacy practices have changed over time in Europe and this may imply a reason for a reform of EU regulation on medicinal products.

\section{INTRODUCTION}

The preparation of medicines in pharmacies is important in order to accommodate individual patients' needs in Europe. This is, in particular, the case if an appropriate authorised medicine does not exist or is unavailable on the market. European Union (EU) regulation determines under which conditions a marketing authorisation is required in order to place a medicinal product on the market and under which conditions a manufacturing and wholesale licence is required. However, it allows some exemptions such as for pharmacy preparations. Some aspects of pharmacy preparations, notably the standards for quality assurance and safety, are not harmonised throughout Europe and therefore fall under the competencies of individual member states.

The Committee of Experts on Quality and Safety Standards in Pharmaceutical Practices and Pharmaceutical Care, hereafter, the Committee of Experts, carried out a survey in 2008-2009 among the state parties to the Convention on the Elaboration of a European Pharmacopoeia. This was coordinated by the European Directorate for the Quality of Medicines \& HealthCare of the Council of Europe. The survey results showed a wide variety between the respondent countries in the quality assurance and standards for medicinal products made in pharmacies. In addition, it demonstrated a gap in standards for quality assurance between medicines prepared in pharmacies and those prepared by the pharmaceutical industry. ${ }^{1}$ The results were discussed among experts from the health authorities and from the field at a workshop in 2009. They aimed to identify criteria and key elements of standards for pharmacy preparation in Europe. ${ }^{2}$ Subsequently, the Committee of Experts proposed a draft resolution for harmonising quality and safety standards for pharmacy preparation of medicinal products in Europe. This led to the adoption of Resolution CM/Res $\operatorname{AP}(2011) 1^{3}$ (hereafter: the Resolution) by the Committee of Ministers of the Council of Europe in 2011 and the committee recommended that member states should amend their legislation in line with the provisions of the Resolution. ${ }^{3}$ The Resolution was put at the disposal of the authorities and pharmacists in order to prevent incidents with medicines prepared in pharmacies which may threaten patients' safety. The Committee of Experts has evaluated the effect of the Resolution in 2013-2014. ${ }^{4}$

Here, we outline the pillars of EU regulation of medicinal products including the circumstances in which the EU regulation does not apply. It provides insight into the recent interpretation of the European Court of Justice (ECJ) concerning the scope of EU regulation of medicinal products and the exceptions to it. Moreover, the article emphasises that relevant standards for safety and quality assurance, such as the ones provided in the Resolution, are needed in Europe in order to protect patient rights and to 
avoid risks to patients associated with pharmacy preparations. Finally, we assess whether change to pharmacy practice over time, as well as recent case law, provide reason for the reform of EU regulation on medicinal products.

\section{THE TWO PILLARS OF EU REGULATION AND THE EXCEPTIONS TO THEM}

\section{The two pillars of regulation}

The system of regulation of medicinal products is built upon two pillars: the marketing authorisation of the medicinal product and the licence for manufacturing and wholesale.

In the EU, medicinal products are regulated by Directive 2001/83/EC ${ }^{5}$ and Regulation (EC) No 726/2004. ${ }^{6}$ The Directive establishes in article 6 (1) that no medicinal product may be placed on the market of a member state unless a marketing authorisation has been issued by the competent authorities of that member state or of the European Commission (EC). Regulation (EC) No 726/2004 lays down the procedure for obtaining a marketing authorisation for certain types of medicinal products (article 3 Regulation (EC) No 726/2004). Every marketing authorisation issued through this procedure is valid throughout the entire EU. In addition, Directive 2001/83/EC states the marketing authorisation procedures for medicinal products that are not addressed in Regulation (EC) No 726/2004. Those products may obtain national approval in one or more member states.

The Directive also establishes that manufacturing of the medicinal products is subject to the holding of a licence issued by the member states (article 40 (1) Directive 2001/83/EC). Moreover, the Directive also states that the wholesale distribution and storage are covered by an authorisation granted by the member state in accordance with this Directive (article 77 (1) Directive 2001/83/EC).

The two pillars only apply in cases where the Directive 2001/ $83 / \mathrm{EC}$ itself is applicable. The Directive applies to any medicinal product that is prepared industrially or manufactured by a method involving an industrial process as determined by article 2 (1) of Directive 2001/83/EC. Products that do not fulfil the conditions of article 2 are not subject to the provisions of the Directive. The meaning of article 2 will be explained in more detail below on the basis of case law of the ECJ: Abcur AB versus Apoteket.

\section{Exceptions to the two pillars of directive 2001/83/EC}

The current Directive 2001/83/EC contains a number of exceptions as regards the above-mentioned pillars. The most important exceptions, as far as they are relevant in relation to the Resolution are: pharmacy preparations, specialties, compassionate use programme and manufacturing licence exception. These are all referred to as exceptions although their scope and legal nature differs.

\section{Pharmacy preparations}

Article 3 of Directive 2001/83/EC states, among other things that the Directive shall not apply to:

Magistral Formula, that is any medicinal product prepared in a pharmacy in accordance with a prescription for an individual patient; and to,

Officinal Formula that is any medicinal product which is prepared in a pharmacy in accordance with the prescriptions of a pharmacopoeia and is intended to be supplied directly to the patients served by the pharmacy in question.
Both definitions contain multiple cumulative requirements. The exceptions only apply if all of the requirements are fulfilled. In that case, neither the marketing authorisation nor the manufacturing and wholesale licences, as established in the Directive, are required. The exception for these requirements is also applicable in the case of the preparation of a medicinal product for which an alternative medicinal product with a marketing authorisation is available on the market. A recent judgement of the ECJ elucidated the requirements.

\section{Abcur $A B$ versus Apoteket}

In the case $A b c u r A B$ versus Apoteket, ${ }^{8}$ Apoteket, a Swedish state-owned company which had the exclusive right to sell medicines to the public until July 2009, produced and sold two medicines (Noradrenalin APL and Metadon APL) without having marketing authorisations for those products. Abcur produced and sold two comparable medicines (Noradrenalin Abcur and Metadon Abcur) for which the company had obtained marketing authorisations. Abcur had put in a claim for compensation for economic loss against Apoteket, because of the promotion of unauthorised medicinal products by Apoteket. The Swedish court suspended the case in order to request a ruling from the ECJ on the meaning of specific provisions of Directive 2001/83/EC.

The ECJ first clarified the scope of Directive 2001/83/EC as determined in article 2. The Directive applies to medicinal products for human use intended to be placed on the market in member states and either prepared industrially or manufactured by a method involving an industrial process. According to the ECJ, a medicinal product manufactured by a method involving an industrial process is characterised through a sequence of operations. These can be either mechanical or chemical, and are intended for the production of large amounts of a standardised product. This implies that Directive 2001/83/EC may apply in the case of standardised production of large amounts of a medicinal product intended for storage or wholesale activities, and in the case of production on a large scale or in series of magistral formulae in batches.

The ECJ ruling then focused on the exceptions where Directive 2001/83/EC does not apply to preparations by pharmacies. For the exceptions in relation to magistral formulae as included in article 3 point 1, the ECJ identified three cumulative requirements in the provision. First, the medicinal product needs to be prepared in a pharmacy. Second, it needs to be prepared in accordance with a medical prescription. Finally, the prescription needs to be for an individual patient. According to the ECJ, the requirements should be interpreted strictly which means that the medicinal product should be prepared in accordance with a medical prescription that needs to be issued by a physician for a specific patient in advance, that is before the medicinal product is prepared for that patient.

The exception for officinal formulae in article 3 point 2 also contains three cumulative requirements. First, the medicinal products must be prepared in a pharmacy. Second, the medicinal products should be prepared in accordance with the prescriptions of a pharmacopoeia. Finally, the medicinal products should be intended to be supplied directly to the patients served by the pharmacy in question. The latter means, as the ECJ clarified, that a medicinal product must be supplied directly by the pharmacy which prepared it to the patients supplied by that same pharmacy. Consequently, the exception of article 3 point 2 does not allow pharmacies to supply officinal formulae to other pharmacies.

The ECJ provided a strict interpretation of the exceptions to the Directive 2001/83/EC, thereby limiting the opportunity for 
pharmacy preparations, but it did not rule on the facts of the specific case before the Swedish court. Therefore, it was up to the Swedish court to ascertain whether the conditions for application of article 2 and article 3, points 1 or 2 of Directive 2001/ $83 /$ EC were satisfied. Furthermore, it should be borne in mind that if Directive 2001/83/EC is not applicable, then this allows for member states to establish national regulations in the matter. These regulations may, for example, include that national authorisations are required for pharmacy preparations.

\section{Novartis versus Apozyt}

Another interesting ECJ case in relation to pharmacy preparations is Novartis versus Apozyt. ${ }^{9}$ Novartis holds the marketing authorisation for the medicinal product Lucentis (ranibizumab) for the treatment of the 'wet' type of age-related macular degeneration (ARMD), a common form of age-related loss of vision. The recommended dose for Lucentis is a single injection of $0.5 \mathrm{mg}$ into the eye. The procedure should be carried out under aseptic conditions. The syringe and the vial are approved for single use only. However, the prefilled syringe contains more than the recommended dose. Therefore when preparing the injection, the physician must expel the excess volume. Meanwhile, Avastin (bevacizumab) is a cancer medicine available as a concentrate that is made up into a solution for infusion (drip into a vein) of Roche Pharma AG, which is not a party to the main proceedings. However, Avastin has been used to treat ARMD off-label already before the marketing authorisation of Lucentis. For reasons related to cost, the off-label use of Avastin has been continued thereafter.

Apozyt is a company that fills syringes with Lucentis and Avastin. These syringes, which contain the exact amount needed for one injection, are dispensed to pharmacies. Apozyt's products are much cheaper because they can fill more syringes with the content of one vial of Lucentis or Avastin. In a court case between Novartis and Apozyt in Germany, the German court referred questions to the ECJ about the interpretation of EU regulations.

It is interesting that the ECJ did not assess, to what extent the products of Apozyt were allowed under the exceptions for pharmacies preparations. The ECJ considered that Apozyt did not need a marketing authorisation for filling syringes for injection with the medicines of Lucentis and Avastin as long as they met the following conditions: The filling of the syringes should not result in any modification of the medicinal product; the filling occurs only on the basis of individual prescriptions; and the injection is administered by the physician who prescribed the medicine. Under those circumstances, the activities could not be equated with a new placing on the market of a medicinal product as included in the first pillar of EU regulation described above.

This verdict of the ECJ clarified the need of a marketing authorisation. The case also related to the need for a manufacturing licence, but that will be discussed in Manufacturing licence.

\section{Specialties}

Member states may, according to article 5 (1) of Directive 2001/ 83 , exclude medicinal products from the provisions of the Directive. Medicinal products provided on the basis of article 5 (1) are also known as specialties. They may include medicinal products imported from other countries or medicinal products manufactured for a specific patient. However, article 5 (1) contains a number of requirements. First, the exception should be in accordance with the legislation in force in the member state.
Second, the exception should be intended to fulfil special needs. Moreover, the medicinal products should be supplied in response to a bona fide unsolicited order, formulated in accordance with the specifications of an authorised healthcare professional and for use by his or her individual patients under the professionals' direct personal responsibility. Consequently, these specialties are medicines that are prescribed on a named-patient basis by a healthcare professional. The ECJ has once again clarified the meaning of the provision and also outlined the scope of the exception for specialties.

\section{European Commission versus the Republic of Poland}

The medicines act in Poland stated that no marketing authorisation was required for medicinal products imported from other member states if those medicinal products contained the same active ingredient, the same concentration and the same dosage form but had a lower price than the medicinal products authorised in Poland. In the case the European Commission versus the Republic of Poland, ${ }^{10}$ the EC held the position that the policy of Poland was contradictory to the requirement for a marketing authorisation in article 6 (1) of Directive 2001/83/ EC, while Poland argued that the provision in their national law was based on the aforementioned exception provided in article 5 (1) of the Directive.

The verdict of the ECJ stated that the substantive rule was that a medicinal product may only be placed on the market if a marketing authorisation has been issued. The exceptions should be interpreted restrictively and the application must remain exceptional in order to preserve the practical effect of the marketing authorisation procedure.

The ECJ subsequently explained the meaning of a 'special need' and a 'bona fide unsolicited order' in article 5 (1). Special needs 'applies only to individual situations justified by medical considerations and presupposes that the medicinal product is necessary to meet the needs of the patient'. ${ }^{11} \mathrm{~A}$ 'bona fide unsolicited order' means 'the medicinal product must have been prescribed by the doctor as a result of an actual examination of his patients and on the basis of purely therapeutic considerations'. ${ }^{12}$

Furthermore, as the ECJ reasoned, the exception for specialties 'can only concern situations in which the doctor considers that the state of health of his individual patients requires that a medicinal product be administered for which there is no authorised equivalent on the national market or which is unavailable on that market'. ${ }^{13}$ Special needs do not exist in cases where there are already authorised medicinal products available on the national market with the same active substances, the same dosage and the same form. It is interesting that financial considerations did not amount to a special need.

For pharmacy practice, it should be borne in mind that the exception for specialties does not apply to cases where an authorised medicinal product with the same active ingredient, the same concentration and the same presentation form, is available. The exception can only be justified by the special needs of the patient and not by financial considerations.

\section{Compassionate use programme}

The third exception concerns the compassionate use programme, which is established in article 83 of Regulation (EC) No 726/ 2004. It constitutes an exception from the prohibition to market medicinal products without a marketing authorisation as in article 6 of Directive 2001/83/EC. Member states may, for compassionate reasons, make a medicinal product available for human use to a group of patients with a chronic or seriously debilitating disease, or whose disease is considered to be life- 
threatening, and who cannot be treated satisfactorily by an authorised medicinal product. The medicinal product should have access to the centralised marketing authorisation procedure in Regulation (EC) No 726/2004. This exemption can only apply to medicinal products that are the subject of an application for a centralised marketing authorisation at the European Medicines Agency or that are undergoing clinical trials. Member states are not obliged to implement the compassionate use option programme in their national laws. However, if they decide to do so, then they have to comply with the requirements of article 83 of Regulation (EC) No 726/2004.

\section{Manufacturing licence}

The last exception concerns a manufacturing licence. Article 40 (2) Directive 2001/83/EC states that a manufacturing licence is not required for preparation, dividing up, changes in packaging or presentation where these processes are carried out, solely for retail supply, by pharmacists in dispensing pharmacies or by persons legally authorised in the member states to carry out such processes. This exception for pharmacies applies regardless of the availability of equivalent authorised medicinal products.

The case of Novartis versus Apozyt is also relevant here because, besides the need for a marketing authorisation discussed above there was also the question of whether a manufacturing licence was required for Apozyt. The German government argued that such an authorisation would not be required since it had established an exception under the aforementioned specialties provision. However, as discussed earlier, that exception only applies in cases where no equivalent product is available. This condition had not been fulfilled in the case of Apozyt's product based on Lucentis, while it may apply in regard to Avastin.

Neither is a manufacturing licence required for the preparation of syringes with Lucentis so long as these processes are carried out, solely for retail supply, by pharmacists in dispensing pharmacies. Whether those conditions are fulfilled is for the national courts to decide. Consequentially, the acceptability of the activities carried out by Apozyt is largely dependent upon national legislation relating to the profession of the pharmacist, the implementation of the specialties regulation and the requirements concerning pharmacy preparations in the practice of the member states.

\section{THE EU REGULATION ON MEDICINAL PRODUCTS AND THE RESOLUTION CONCERNING PHARMACY PREPARATION}

In the EU, as explained above, medicinal products are regulated by Directive 2001/83/EC and Regulation (EC) No 726/2004. This EU legislation offers some space for pharmacy preparations, but only under certain strict conditions as defined in these regulations. Pharmacies specialised in preparation may not, however, always fulfil these strict conditions.

In the case that Directive 2001/83/EC does not require a marketing authorisation for the medicinal product, member states are allowed to establish national regulations for pharmacy preparations. These regulations may, for example, stipulate that national authorisations are required for pharmacy preparations. For pharmacy preparations, which are outside the scope of Directive 2001/83/EC, the Resolution provides guidance to the member states.

The Resolution, which is adopted by 36 member states, provides a means of establishing standards for safety and quality assurance for pharmacy preparations. The Resolution is not legally binding, but expresses the wish of the member states to have the option of centralised pharmacy preparation and to standardise the safety and quality standards for pharmacy preparations. It helps pharmacists to determine what adequate standards of quality are. Before preparation, a risk assessment should always be carried out by the pharmacist in order to define the level of the quality assurance system which should be applied to the preparation process of the medicinal product. The Resolution recommends that the Good Manufacturing Practice Guidelines $^{1415}$ are used as a reference for an appropriate quality system for 'high-risk preparations', and that the PIC/S GPP Guide $^{16}$ be used for 'low-risk preparations'. The Resolution also discusses multiple other elements that may be incorporated into a safety and quality assurance system for pharmacy preparations. These include: a product dossier containing product-specific quality properties and site-specific manufacturing conditions; criteria for a marketing authorisation; labelling; compliance with pharmacopoeial requirements; authorisation for pharmacies or licences for companies making preparations for pharmacies; transparency and safety; communication and information to patients; and distribution of pharmacy preparations.

The centralisation and specialisation of pharmacy preparation has occurred in multiple member states, whereas, at the same time, an increasing number of pharmacies lack the facilities and competence to fulfil the quality standards for the preparation of medicinal products. Some pharmacies may have discontinued the preparation of magistral and officinal medicinal products and, instead, use the services of pharmacies specialised in pharmacy preparation. Specialised pharmacies are usually in a better position than pharmacies that prepare medicinal products on a small scale. They are better able to invest in quality assurance and safety standards such as those related to personnel, premises and equipment. Member states have, indeed, established national regulations with regard to specialised pharmacies and have taken the safety and quality assurance elements of the Resolution into account. This is presented in a separate article. ${ }^{4}$

\section{DISCUSSION AND CONCLUSIONS}

The system of European regulation of medicinal products has two pillars: the marketing authorisation of the medicinal product and the manufacturing licence. The EU legislation on medicinal products-Directive 2001/83/EC and Regulation No (EC) $726 / 2004$ - provides a number of exceptions through which the EU legislation or specific provisions, for example, the requirement for a marketing authorisation, do not apply. The ECJ has provided an interpretation of the legislation which established that a wide scope of products is subject to the EU legislation, while, in turn, restricting the products subject to the exceptions. Their interpretation of Directive 2001/83/EC limits the space for pharmacy preparations. It is questionable whether this interpretation takes into account the fact that the magistral formula and officinal formula are not available for multiple patients whose pharmacy has stopped pharmacy preparation. These non-preparing pharmacies subcontract this activity to pharmacies specialised in pharmacy preparation and dispensing.

The limited space for pharmacy preparations raises the question of whether the EU legislation Directive 2001/83/EC needs to be amended. Given that the ECJ restricts the products subject to the exceptions in the EU legislation, it is important to consider whether healthcare and the rights of patients are sufficiently guaranteed in cases where patient needs cannot be fulfilled by an authorised medicinal product manufactured by the pharmaceutical industry. Today, pharmacies may decide to make use of the services offered by pharmacies specialised in preparation to fulfil special patient needs. Pharmacies specialised 
in pharmacy preparation also fulfil an important role in the supply of medicinal products, for example, when the availability of an industrial product with a marketing authorisation has been interrupted or stopped altogether. However, the supply of medicinal products by specialised pharmacies to local pharmacies is not allowed on the basis of article 3 of Directive 2001/ 83/EC as has been demonstrated in the Abcur v Apoteket case. The exception of article 5 of that Directive with regard to 'specialties' might be an option to allow pharmacies specialised in the preparation of medicinal products to dispense their products, but, this is only if the conditions of article 5 are fulfilled. Whether article 5 is a real option that fits in with EU legislation needs further evaluation. If none of these exceptions apply, then the two pillar system of Directive 2001/83/EC is fully applicable. That means that a marketing authorisation of the medicinal product and a manufacturing licence for the pharmacy are required.

If the conditions in the definition of pharmacies' preparations in Directive 2001/83/EC are fulfilled, then the Directive does not apply and member states may establish national regulations for pharmacy preparations. The national regulations may be based on the standards for safety and quality assurance referred to in the Resolution including the situation in which there is external supply of medicinal products by specialised pharmacies

\section{What this paper adds?}

What is already known on this subject?

- The European Union (EU) regulation determines under which conditions a marketing authorisation is required in order to place a medicinal product on the market and under which conditions a manufacturing and wholesale licence is required. However, EU regulation allows some exemptions such as for pharmacy preparations.

- It is common practice throughout member states to allow pharmacy preparations for the treatment of patients for which no licensed medicinal product is available on the market. Since 2011, the member states of the Council of Europe are recommended to use the Council of Europe Resolution on quality and safety standards for pharmacy preparations for the special needs of patients.

\section{What this study adds?}

- The article outlines the pillars of European Union (EU) regulation of medicinal products including the circumstances in which the EU regulation does not apply. It also provides insight into the recent interpretation of the European Court of Justice (ECJ) concerning the scope of EU regulation of medicinal products and the exceptions to it.

- Relevant standards for safety and quality assurance, such as the ones provided in the Resolution, are needed in Europe in order to protect patient rights and to avoid risks associated with pharmacy preparations.

- In the case Abcur $A B$ versus Apoteket, the $E C J$ provided a strict interpretation of the exceptions to the Directive 2001/ 83/EC, thereby limiting the opportunity for pharmacy preparations. If the practices concerning pharmacy preparation in European countries do not fit within current EU legislation, then there may be a real problem for individual patient care. to dispensing pharmacies. This may reduce the risk to patients associated with pharmacy preparation.

Previous research shows that there is large variation in the standards and policies regarding pharmacy preparations within Europe. ${ }^{1}$ However, it is common practice throughout member states to allow pharmacy preparations for the treatment of patients for which no licensed medicinal product is available on the market. ${ }^{4}$ Further evaluation is required to see whether the pharmacy preparations and the related national policies are in line with current EU legislation and the Resolution, and the consequences thereof.

If the practices concerning pharmacy preparation in European countries do not fit within current EU legislation, then there may be a real problem for individual patient care. We feel that there should be sufficient space for the preparation of medicines in pharmacies in order to accommodate individual patients' needs in Europe, provided that an authorised medicine does not exist or is unavailable on the market. Pharmacy preparations should be able to fulfil all special patient needs, including the needs of patients belonging to a pharmacy that has stopped preparation and that has subcontracted the pharmacy preparation to a pharmacy specialised in preparation. However, this subcontracting is, in our opinion, only in the interest of the patient under the condition that the pharmacy specialised in preparation fulfils all the safety and quality assurance elements mentioned in the Resolution.

\section{Author affiliations}

${ }^{1}$ Ministry of Health, Welfare and Sport, Health Care Inspectorate, Utrecht, The Netherlands

${ }^{2}$ Department of Pharmacoepidemiology \& Clinical Pharmacology, Utrecht Institute for Pharmaceutical Sciences (UIPS), Utrecht University, Utrecht, The Netherlands

${ }^{3}$ Capital Region Pharmacy, Herlev, Denmark

${ }^{4}$ European Directorate for the Quality of Medicines \& HealthCare (EDQM), Council of Europe, Strasbourg, France

${ }^{5}$ Pharmaceutical law University of Utrecht, Utrecht, The Netherlands

${ }^{6}$ Department of Clinical Pharmacy and Toxicology, Maastricht University Medical Centre, Maastricht, The Netherlands

${ }^{7}$ CAPHRI School for Public Health and Primary Care, Maastricht, The Netherlands

Acknowledgements The authors thank delegates of the countries of the Council of Europe.

Contributors HPAS prepared the manuscript. JL, VNH, SW, MHS and CN revised it critically. All authors gave final approval of the original manuscript and its revised version. Competing interests None declared.

Provenance and peer review Not commissioned; internally peer reviewed.

\section{REFERENCES}

1 Scheepers HPA, Busch G, Hofbauer E, et al. Abridged survey report on quality and safety assurance standards for the preparation of medicinal products in Pharmacies. Pharmeuropa 2010;22.

2 "Promoting Standards for the Quality and Safety Assurance of Pharmacy-Prepared Medicinal Products for the Needs of Patients", (24 September 2009 at the European Directorate for the Quality of Medicines \& HealthCare (EDQM), Council of Europe, in Strasbourg). http://www.edqm.eu/en/quality-and-safety-standards-1244. html (accessed 17 Oct 2014)

3 Resolution CM/ResAP(2011)1 on quality and safety assurance requirements for medicinal products prepared in pharmacies for the special needs of patients. Council of Europe.

4 Scheepers HPA, Neerup Handlos V, Walser S, et al. Impact of the Resolution on quality and safety Assurance standards for the preparation of medicinal products in pharmacies. doi:10.1136/ejhpharm-2016-001017

5 Directive 2001/83/EC of the European Parliament and of the Council of 6 November 2001 on the Community code relating to medicinal products for human use.

6 Regulation (EC) No 726/2004 of the European Parliament and of the Council of 31 March 2004 laying down Community procedures for the authorisation and supervision of medicinal products for human and veterinary use and establishing a European Medicines Agency. 


\section{Original article}

7 Ebbers HC, Langedijk J, Bouvy JC, et al. An analysis of marketing authorisation applications via the mutual recognition and decentralised procedures in Europe. Eur J Clin Pharmacol 2015;71:1237-44.

8 Joint cases C-544/13 and C-545/13 Abcur v Apoteket [2015].

9 C-535/11 Novartis v Apozyt [2013].

10 C-185/10 Commission v Poland [2012].

11 C-185/10 Commission v Poland [2012], paragraph 34.

12 C-185/10 Commission v Poland [2012], paragraph 35.
13 C-185/10 Commission v Poland [2012], paragraph 36

14 Good manufacturing practices (GMP): practices as specified in European Commission Directive 2003/94/EC.

15 EudraLex, Volume 4, on guidelines for good manufacturing practices for medicines for human and veterinary use.

16 "Guide to good practices for the preparation of medicinal products in health care establishments", in Pharmaceutical Inspection Convention Pharmaceutical Inspection Co-operation Scheme (PIC/S) Guide PE 010 